\title{
КОМУНИКАЦИОНЕН ОКТАГОН: АСПЕКТИ НА ИНТЕЛИГЕНТНОСТТА ПРЕЗ ПРИЗМАТА НА КОМУНИКАЦИОННАТА СРЕДА
}

\author{
Айля Илиязова \\ COMMUNICATION OCTAGON: ASPECTS OF THE INTELLIGENCE \\ THROUGH THE PRISM OF THE COMMUNICATION ENVIRONMENT \\ Aylya Ilyazova
}

\begin{abstract}
The aim of the paper is to highlight certain aspects of the semantic profile of the concept of "intelligence" through a model called "communication octagon", focusing on the theory of dynamics of communication links, and to analyze the interaction between the intelligent system and the social environment. The focus of interest in the study is human intelligence, based on individual biological differences, which can be modified as a result of construction and transmission of knowledge, mutual emotional transfer, making cognitive requirements (directed inwards and outwards, towards the environment), and as a result of dynamic social interactions.
\end{abstract}

Key words: intelligent behavior, knowledge, communication, abilities

DOI: https://doi.org/10.46687/BRFA3869

Комуникационното поведение може да улесни или да влоши процеса на социализация на индивида, тъй като комуникацията не е просто обмен на информация или на значения, а до голяма степен и обмен на нагласи. В такъв контекст средата се разглежда и като сбор от комуникационни връзки, като фокусът е насочен към динамиката на тези връзки (Mohr 2006: 86). Понятията интелигентност и интелигентно поведение в настоящата работа се дефинират в контекста на проблема за комуникационните връзки и комуникационното поведение на индивидите. Под интелигентно поведение се разбира специфично взаимодействие между интелигентна система и среда, което предполага възможност да се знае, да се разсъждава логично и да се действа целенасочено. Като интелигентна система в научния дискурс се интерпретира такава система, която „винаги е поставена в социална среда", а пример за такава система е и човекът (Unseld 1990: 10).

Всяка интелигентна система притежава потенциала да наблюдава обкръжаващата я среда, да я проучва, като при това ,, [...] количествено 
и качествено да разширява знанието си" (Unseld 1990: 10) ${ }^{1}$. Наличието на такава социална среда, както и взаимодействието между система и среда създават необходимите условия за развитие на човешкия интелект, като ориентировъчната и информативната функция на обкръжаващата среда са сред най-релевантните. Изследователи се фокусират при това и върху учебната среда, насочена към определена цел, възникнала при симулиране на реални учебни ситуации, предявяващи определени претенции в когнитивен план спрямо интелигентната система (Messner, Blum 2006: 5).

Основната изследователска теза в настоящото изложение се разгръща посредством:

- теорията за множеството интелигентности на Хауърд Гарднър като „плуралистична визия за ума, при която се вземат предвид различните аспекти на познанието“ (Gardner 2014: 15) и „разликите в социалния и културния контекст, в който растат младите хора“ (Gardner 2014: 8);

- триархичната теория за успешната интелигентност на Робърт Стърнбърг, разглеждаща три взаимосвързани аспекта на интелигентността: аналитични, творчески и практически способности (Sternberg, Williams 2014: 207);

- теорията за структурната динамика на Дейвид Кантър, която очертава четири роли за ефективна комуникация: двигател, опонент, последовател и наблюдател.

Понятието интелигентност е в основата на многоаспектни интерпретации, както и на поляризирани научни дебати, някои от които в тази работа ще бъдат привлечени с една единствена цел: да се открои ефектьт от динамичността на комуникационната среда върху модифицирането на човешката интелигентност. Това рамкиране на изследването не цели ограничаване на перспективите, а по-скоро задълбочаване и акцентиране на отделни аспекти на понятието интелигентност, които ще се откроят с помощта на предложения в работата модел под името комуникационен октагон. Идеята да се изразят определени връзки между осем аспекта, имащи отношение към процеса на комуникация, от една страна, и към процеса на модификация на

\footnotetext{
${ }^{1}$ Преводът мой, А. И.
} 
интелигентността, от друга, е инспирирана до известна степен от т. нар. когнитивен хексагон, предложен от SOAP (State of the Art Report) ${ }^{2}$.

Моделът комуникационен октагон няма допирни точки със съдържанието на гореспоменатия когнитивен хексагон, освен идеята за взаимосвързаност между отделните компоненти. Използваната в работата фигура препраща към т. нар. правилен осмоъгълник, чиито страни и ъгли са равни: предложените осем аспекта, оформящи осмоъгълника, са в еднаква степен релевантни за работната теза в изследването. Връзките между тях изграждат своеобразна система, в която може да се открие:
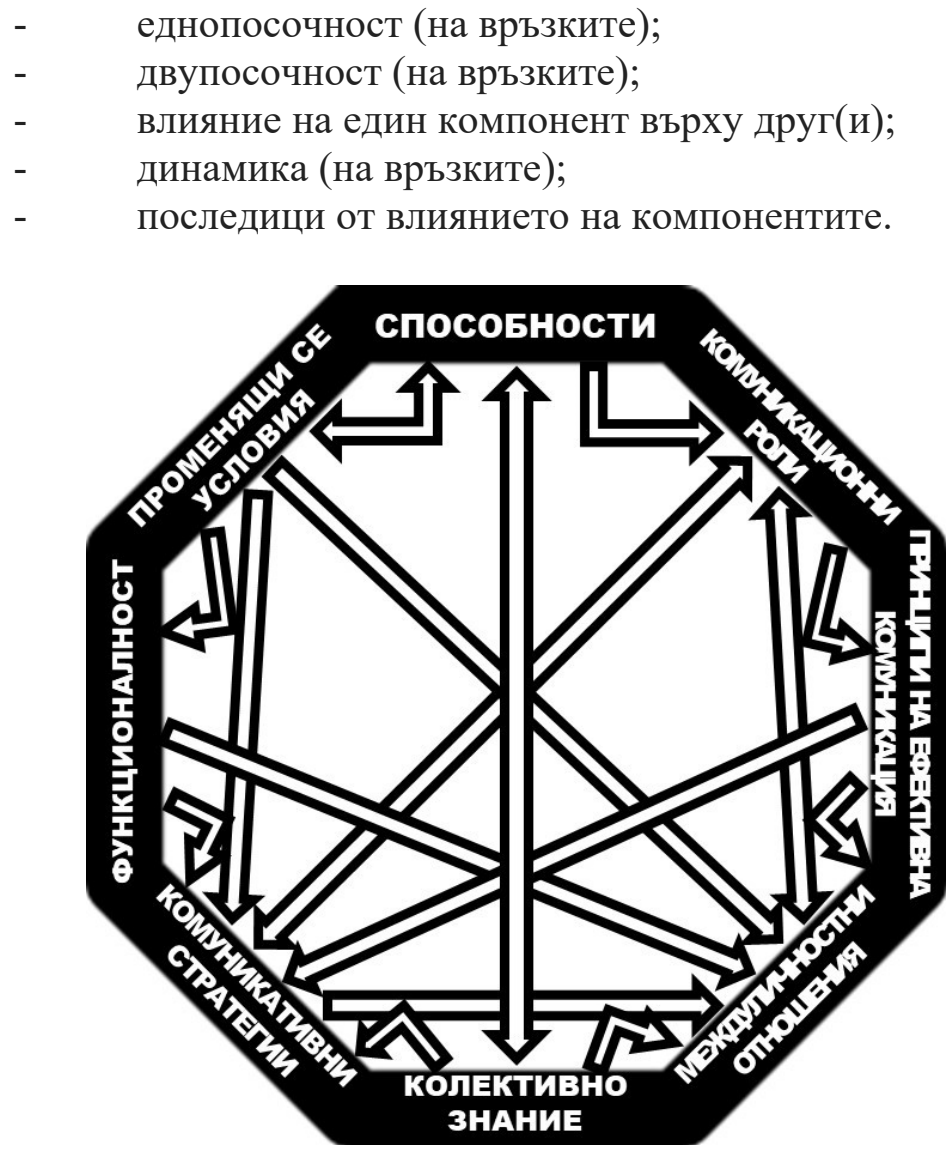

2 SOAP (State of the Art Report) е спонсориран от фондацията Sloan и представен от Хауърд Гарднър през 1987 (Gardner 1987: 37; Gardner 2008). Материальт на Гарднър, който е свързан с отделните поддомейни на когнитивната наука, остава непубликуван, но въпреки това оставя следа в историята на когнитивните изследвания. 


\section{Способности}

Интелигентността е „овладяване и усъвършенстване на способности, които се развиват в дадена среда“" (Stoyanov 2015: 31). Човешките индивиди се различават помежду си „по степента на уменията си и по тяхната комбинация“ (Gardner 2014: 16). Според триархичната теория за успешната интелигентност на Робърт Стърнбърг основополагащи са три взаимосвързани аспекта на интелигентността: аналитични, творчески и практически способности (Sternberg, Williams 2014: 207). Тези аспекти са относително автономни, а върху тяхното „действително изразяване“ влияе средата: взаимодействието гени - среда се отнася до идеята, „че генетичните и екологичните влияния могат да се комбинират, за да създадат резултати, които е възможно да са неочаквани само на базата на единия фактор“" (Sternberg, Williams 2014: 239).

\section{Комуникационни роли}

Основна причина за съществуването на различия между човешките индивиди, потопени в съответна среда, е наличието на разлики в техните роли спрямо обкрьжаващата ги среда (Canter 2018: 9). Концептуалните системи на различните участници в комуникацията са различни, те предизвикват различни преживявания, които от своя страна са причина за различните перспективи (Canter 2018: 9). В своя модел от 1927 г. Кантър разграничава четири роли за ефективна комуникация: 1. двигател; 2. опонент; 3. последовател; 4. наблюдател. Без първата роля, тази на двигателя, комуникацията би била без посока, ако я няма втората роля - опонентът комуникацията би останала без корекция. Без последователя не би било възможно завършването на идеята, а без наблюдателя комуникацията ще е без перспектива.

\section{Принципи на ефективна комуникация}

Ефективната комуникация изисква: яснота, краткост, конкретност, достоверност, правилност, адекватност, пълнота и креативност. Тези основни принципи могат да бъдат съотнесени към основните роли за ефективна комуникация и към евентуалните последици от отсъствието им, при което се открояват следните закономерности:

ако на комуникацията ѝ липсва посока, ще бъдат нарушени принципите за правилност и конкретност; 


\section{Годишник на ФХН, XXXII A}

- ако на комуникацията ѝ липсва корекция, ще бъдат нарушени принципите за адекватност и достоверност;

- ако на комуникацията ѝ липсва завършване на идеята, ще бъдат нарушени принципите за пълнота и креативност;

- ако на комуникацията ѝ липсва перспектива, ще бъде нарушен принципът за яснота.

\section{Междуличностни отношения}

Оказва се, че междуличностната интелигентност, анализирана от Х. Гарднър, „не зависи от езика“ (Gardner 2014: 28), но позволява на хората да разбират другите, както и да работят съвместно с тях. В работата вече бе направено уточнение как се тълкува понятието интелигентно поведение: онова специфично взаимодействие между интелигентна система и среда, което изисква и целенасоченост. Целенасочеността предполага и адекватност в поведението, докато „поведенческата неадекватност усложнява човешките отношения“ (Kamenov 2008: 11-13). В многоаспектния подход към интелигентността „начинът, по който индивидът е взаимодействал със средата“ се обозначава като „предишен опит“ (Gardner 2014: 263). От това взаимодействие на индивидите със социалната среда зависи и мотивацията им, т. е. тя не е просто „функция на компетентността“, а постепенно ,това взаимодействие придобива субективен характер и започва да ръководи индивидуалното поведение“ (Vygotsky 1978, цит. по Gardner 2014: 245). Развитието на интелигентността е възможно „чрез динамиката между компетенциите на отделния индивид и обществените ценности и институции“ (Gardner 2014: 250). Способността и готовността за комуникация трябва да се анализират винаги в контекста на наличните времеви ресурси (Mayrhofer-Battlogg 2018: 347).

\section{Колективно знание}

В основата на различните теории на знанието е анализът на различни постулати, които се отнасят и до отделни аспекти на интелигентността (при което се оформя и семантичният профил на понятието интелигентност):

- „знанието, което всеки от нас овладява през живота си, не може да се вземе наготово от другите, а трябва да се конструира“ 
(Glasersfeld 2005: 1); ${ }^{3}$ в този контекст интелигентността „съответства на изпълнението на задачата“, т. е. важен е „начинът, по който се изпълнява задачата“" (Gardner 2014: 48-49); дадено действие би могло да бъде охарактеризирано като интелигентно, ако се знае с каква цел се извършва, какво е неговото предназначение, както и дали са съществували други възможности (Gardner 2014: 49);

знанието е „система от информация“ (Vasilev, Chorbadziyska, Belyovska 2017: 38); в този контекст традиционната концепция определя интелигентността като „изчислителен капацитет капацитетът да се обработи определен вид информация“" (Gardner 2014: 17); информационните стимули - външни и вътрешни - са катализаторите за проявената интелигентност;

„знанието е инструмент на приспособяването - a не огледало на реалността, т. е. на света, какъвто би бил без нас" (Glasersfeld 2005: 1); в този контекст като интелигентност се определя способността за адаптация към средата, а тази адаптация е възможна „чрез умението да се решават проблеми“ (Gardner 2014: 17);

символната система като носител на различни форми на информация е релевантна за продуктивността на човешките общности; в този контекст интелигентността „трябва да може да се кодира в [...] културологична система от знаци [...] езикът, изображенията и математическите знаци““ (Gardner 2014: 18);

само комуникацията ни дава възможност да събираме спомени и да ги използваме активно, защото ,човек си спомня само онова, което е запомнил при комуникация и което може да се локализира в рамките на колективното съзнание“" (Assmann 2005: 36-37); комуникационните връзки от своя страна определят (интелигентното) поведение (Burkart 2000: 361);

създадените продукти на цивилизацията са възможност да „се трупа и предава познание“ (Gardner 2014: 17); в този контекст като интелигентност се определя ,способността да се решават проблеми и да се създават продукти, които са ценни за дадена културна среда или общество“ (Gardner 2014: 17).

${ }^{3}$ Разговор на Ернст фон Глазерсфелд с журналиста Робърт Шчепел, в science.ORF.at, превод мой, А. И. 


\section{Годишник на ФХH, XXXII A}

\section{Комуникативни стратегии}

Интелигентността предполага приспособяване към факторите на средата, като адаптацията е в зависимост от индивидуалните различия на индивидите. Ефективните стратегии на общуване водят до сформиране на екипи, в които „има споделяне, но не еднаквост, [...] има общи цели, но не и еднакви умения“ (Gardner 2014: 269). Индивидуалността е основополагаща, за да има контакт; тя е предпоставка, за да се осъществи „диалогично мислене“ (Korpiun 2015: 2). Диалогичната комуникация се посочва като стратегически важна за промяна на перспективата, а като неин най-важен метод се разглежда личният разговор - диалогът (Mayrhofer-Battlogg 2018: 264).

Четири основни компонента на диалога анализира Уилям Исаакс, когато описва т. нар. капацитети за ново поведение: вслушване (активно слушане) (zuhören), респектиране (respektieren), суспендиране (suspendieren) и артикулиране (artikulieren) (Isaacs 2011: 123-124). Вслушването (активното слушане) се интерпретира като процес на вътрешно мълчание, което спомага да се вникне в същността на това, което ни се внушава от комуникационния партньор; в този контекст вслушването се свързва с партиципиране.

Респектирането се обвързва с идеята за цялостния характер на света около нас: това, което един притежава като предишен опит, като преживявания, би могло да засегне и някой друг като част от тази цялостност. Това не ни дава право да игнорираме или напълно да изключваме другите: част от процеса на адаптация е да приемаме другите с респект, като с това показваме и респект към самите себе си. В този контекст респектирането се свързва с кохерентност. Суспендирането намира израз в това да представяме личното си мнение така, че да се даде възможност (както на нас самите, така и на другите) да възприемем и осъзнаем идеите си. Като компонент на диалога суспендирането е приемане и осъзнаване на пораждащите се мисли и чувства, както и наблюдаване, без да се налага принудително да се действа. В този контекст суспендирането се свързва с осъзнаване. Артикулирането се свързва с разгръщане: имплицитното се разгрьща в експлицитния, видим свят, за да се разгърне след това отново в невидимост (Isaacs 2011: 141). ${ }^{4}$

${ }^{4}$ В трета глава „Prognostische Intuition“ на книгата „Dialog als Kunst gemeinsam zu denken: Die neue Kommunikationskultur in Organisationen“" У. Исаакс описва т. нар. прогностична интуиция, като разсъждава върху въпроса как може да се предвидят и 


\section{Функционалност}

Функционалният аспект на комуникацията се изразява във въпроса „за намеренията, интенцията и интересите, които предизвикват комуникационния процес“"5. Интелигентността се интерпретира като „разлика между индивидите“, като индивидуалните различия са по отношение на интересите (Gardner 2014: 48). Диалогичната комуникация предявява изисквания към отношенията на ниво интерактивни контакти, които се активират чрез емоциите и духовния обмен (Mayrhofer-Battlogg 2018: 362). Когнитивни моменти, които съзнателно трябва да бъдат усвоени, имат отношение към ,[...] доверяване на интерактивната помощ от страна на партньора“, както и към умението да се комуникира в междукултурен контекст (Koeva 2017: 21). Специфичността на съответната култура би могла да е основа за „погрешни интерпретации на начините на изразяване и поведение на партньора“ (Koeva 2017: 22). Понятието комуникативна чувствителност е определящо в случаите, когато е необходимо да се избегне фатално развитие на комуникативна ситуация (MayrhoferBattlogg 2018: 371 ).

\section{Променящи се условия}

Практическите способности като един от аспектите на интелигентността се отнасят до три функции:

- адаптация към обкрьжаващата ни среда;

- създаване на нови типове среда;

207).

- подбор на нови типове среда (Sternberg, Williams 2014:

Интелигентността предполага и адекватна реакция в определена ситуация на ,,емоционалните въздействия, възникващи от обкръжаващата среда“ (Stoyanov 2015: 32). Адекватната реакция се

осъзнаят факторите, които определят даден разговор. Към четирите роли за ефективна комуникация от комуникационния модел на Д. Кантър от 1927 г. Исаакс съотнася четирите компонента на диалога: 1. двигател - артикулиране; 2. последовател вслушване, активно слушане; 3. опонент - респектиране; 4. наблюдател - суспендиране (Isaacs 2011).

5 Цитатът е от лекционен курс „Комуникации в социалните системи“ на авторски колектив към Химикотехнологичен и металургичен университет, секция Хуманитаристика и осигуряване на качеството на обучението (2007: 12) < http:// else.uctm.edu/users/3/books/Komunikacij-OET.pdf (status 20.03. 2021)>. 


\section{Годишник на ФХH, XXXII A}

свързва с проницателността, която дава възможност на индивида, наблюдавайки внимателно различни видове поведение, „провокиращи среда на неопределеност", да прогнозира евентуално бъдещо поведение на комуникационните партньори и да рефлектира върху „евентуални последствия от такова поведение“ (Kamenov 2012: 64). Променящите се условия са причина по-скоро да се правят опити да се проследят във времето „отделни елементи на ситуацията, за които има сравнително най-пълна информация“ (Kamenov 2006: 9), като е необходимо да бъде изпълнено и едно важно условие (което е и найпроблематично): средата, в която се намират хората, трябва да притежава достатъчна стабилност, устойчивост и прогнозируемост, т. е. светьт да не претърпи промяна по отношение на важни за хората аспекти, за да не бъдат обречени на провал техните предположения (Mengov 2014: 3-4).

Съществуващите канали за комуникация могат да бъдат променяни от технологиите, но е важно да се осъзнае разликата между технологии, които променят тези канали и технологиите, които променят средата за всички комуникации. Новите медии, уеб 2.0, уеб 3.0 , а вече и уеб 4.0, променят средата изцяло и не се превръщат просто в допълнителен инструмент към комуникационния микс. Те изискват изцяло нов начин на мислене.

\section{Изводи}

Взаимосвързаността между отделните компоненти допринася за целостта на предложения в работата комуникационен октагон. След направения анализ на релациите между отделните компоненти на преден план се откроиха 16 (шестнадесет) особено значими за целите на работата връзки.

1. Компонентьт колективно знание има отношение към ефективните стратегии на общуването в контекста на приспособяването на индивидите към факторите на средата. Знанието като „инструмент на приспособяването“ е важно при промяна на перспективата (връзката между двата компонента в октагона е еднопосочна).

2. Компонентьт комуникативни стратегии, който води до сформиране на екипи „на споделеност и на различни умения“, в комуникативния октагон има насоченост към компонента междуличностни отношения - стратегиите партиципиране, кохерентност, осъзнаване и разгръщане са базисни при специфичното 
взаимодействие между индивидите. Особено важна е динамиката между индивидуалните способности на отделния индивид и обществените ценности.

3. Връзките между други два компонента от октагона способностите и променящите се условия - представляват взаимодействието гени - среда: тук връзките са двупосочни. Генетика и екология в тяхната комбинация водят до модифициране на интелигентността, което би могло да е непостижимо, ако действа само единият фактор.

4. Компонент способности и компонент колективно знание: интелигентността като способност да се създават продукти с особена важност и значимост има отношение към колективното знание, тъй като създадените продукти от своя страна са начин да се предава познание на следващи поколения, както и на други културни среди и общества. Връзките между двата компонента в октагона са двупосочни: знанието, което индивидът овладява, не се приема в готов вид, а се осъзнава в процеса на индивидуално, субективно конструиране.

5. Между компонента функиионалност и компонента междуличностни отношения съществува следната релация: индивидуалните интереси регулират начина на поведение, което всеки един участник следва при интерактивните контакти. Комуникативната чувствителност, емоционалният трансфер и духовният обмен са определящи за динамиката на интерактивния диалог (връзката в октагона е еднопосочна).

6. Компонент променящи се условия и компонент комуникативни стратегии: създаването на нови типове (комуникационна) среда е в резултат и на ефективността на стратегии за разгръщане на капацитети за ново поведение. Връзката в октагона е еднопосочна.

7. Връзката между компонента променящи се условия и компонента функционалност се изразява в следното: подборът на нови типове (комуникационна) среда би могъл да доведе и до промяна на интенцията, на намеренията на комуникационните партньори. Адаптацията към средата е свързана с преодоляване на когнитивни изисквания, като индивидуалните различия по отношение на интересите допринасят за това всеки индивид да подходи субективно при този подбор на нови типове среда (връзката в октагона е еднопосочна).

8. Своеобразни връзки се откриват и между компонент принципи на ефективна комуникаџия и компонент комуникативни 


\section{Годишник на ФХН, XXXII A}

стратегии. При анализа се оформи следната закономерност между принципи и т. нар. капацитети за ново поведение (Isaacs 2011: 123-124):

- принцип за адекватност и принцип за достоверност партиципиране (участие);

- принцип за правилност и принцип за конкретност кохерентност (свързаност);

- $\quad$ принцип за яснота - осъзнаване;

- принцип за креативност и принцип за пълнота разгръщане.

9. Компонент комуникащуиони роли и компонент принцуипи на ефективна комуникация - при липса на комуникативни роли ще бъдат нарушени принципите на ефективна комуникация:

- $\quad$ без роля двигател комуникацията няма да има посока ще бъдат нарушени принципите за правилност и конкретност;

- $\quad$ без роля опонент комуникацията няма да има корекция - ще бъдат нарушени принципите за адекватност и достоверност;

- без роля последовател в комуникацията няма да има завършек на идеята (идеите) - ще бъдат нарушени принципите за пълнота и креативност;

- без роля наблюдател в комуникацията няма да има перспектива - ще бъде нарушен принципът за яснота.

10. Връзките между компонент комуникационни роли и компонент комуникативни стратегии са двупосочни: към четирите роли се съотнасят четирите компонента на диалога (вслушване/ активно слушане, суспендиране, респектиране и артикулиране):

- роля двигател - артикулиране;

- роля наблюдател - суспендиране;

- роля последовател - вслушване (активно слушане);

- роля опонент - респектиране.

Ролята на двигателя се изразява в експлицитно представяне на концепции, като се мотивира за действие. Ролята на наблюдателя намира израз в приемане и осъзнаване на представените концепции, като се наблюдава без да се налага принудително да се действа. Роля на последователя: да се вслушва и да вниква в същността на изразените концепции, като изрази осъзнаването чрез партиципиране (участие в действие). Роля на опонента: да представи идеите си в условия на кохерентност (свързаност), като даде възможност на другите участници 
в комуникацията да възприемат и да осъзнаят тези идеи. Това негово действие ще доведе до респектиране.

11. Компонент способности и компонент комуникационни роли: анализът открои еднопосочна връзка - индивидуалните биологични различия са релевантен фактор, влияещ върху различните комуникационни роли, които индивидите изпълняват, потопени в конкретна среда. Различните перспективи са в резултат от спецификата на концептуалните системи на комуникационните партньори.

12. Двупосочни връзки се откриват между компонент комуникационни роли и компонент междуличностни отношения. Съвместната дейност е основана на поведенческа адекватност, а тя от своя страна е свързана с целенасоченост при взаимодействие на интелигентната система и (комуникационната) среда. Различната степен на мотивираност не е просто функция на компетентности, тя се базира и на предишния опит на индивида, интерпретиран като начин за взаимодействие със средата.

13. Еднопосочна в комуникационния октагон е връзката между компонент колективно знание и компонент междуличностни отношения. Знанието се конструира от всеки индивид и в този процес е важен начинът, по който се изпълнява дадена задача: това би могло да повлияе на качеството на междуличностните отношения. Ако е ясна целта, според която се извършва задачата, т. е. налице е целенасоченост, както и какво е предназначението на дадено действие, това може да позволи на хората да работят съвместно. В противен случай поведенческата неадекватност може да доведе до компликации в междуличностните отношения.

14. Между компонент променящи се условия и компонент междуличностни отношения в октагона се откроява еднопосочна релация. Предишният опит на индивида влияе върху индивидуалното му поведение: понятието прогностична интуищия се свързва с възможността „средата на неопределеност“ да бъде поне малко по-прогнозируема, а това изисква проницателност, която дава възможност на индивида да рефлектира върху някои евентуални последствия от различни видове поведение на комуникационните партньори. Различният начин на взаимодействие със средата, т. е. различният предишен опит на индивида влияе върху индивидуалното поведение на всеки един от комуникационните партньори, което поражда различен тип междуличностни отношения. 


\section{Годишник на ФХH, XXXII A}

15. Еднопосочна е връзката и между компонент приниипи на ефективна комуникация и компонент междуличностни отношения. Ако бъдат нарушени принципи на ефективна комуникация, се наблюдават различен тип междуличностни отношения:

- неадекватността (нарушен принцип за адекватност) усложнява междуличностните отношения - партиципирането би било невъзможно, а с това и промяната на перспективата;

- $\quad$ недостатъчната яснота (нарушен принцип за яснота) води до погрешни интерпретации на начините на изразяване на комуникационните партньори;

- $\quad$ липсата на конкретност и на правилност (при нарушени принцип за конкретност и принцип за правилност) може да затормози степента на свързаност на участниците в комуникационния процес.

16. Връзката между компонент функционалност и компонент комуникативни стратегии в октагона е еднопосочна. Степента на комуникативна чувствителност на комуникационните партньори влияе при избора на комуникативни стратегии - активното вслушване във внушенията на партньорите в процеса се свързва с партиципиране, което води до промяна в комуникационното поведение. Индивидуалната интенция, индивидуалните намерения, предизвикващи комуникационния процес, могат да бъдат:

- д доминантни в рамките на интерактивните контакти;

- $\quad$ подчинени в рамките на интерактивното взаимодействие.

По този начин стратегиите от своя страна биха могли да предизвикат промяна на перспективата.

\section{Заключение}

Различни аспекти на познанието предпоставят различни аспекти на интелигентността, при което се открояват човешките когнитивни качества и компетентности, които контрастират, а не се унифицират, поради своята биологична основа. Във всеки индивид те работят в синхрон, а в сложните социални роли, които му се налага да изпълнява, ce включват комбинации от тези аспекти, формиращи лично, непредвидимо и изненадващо поле от ресурси и възможности.

\section{ИЗПОЛЗВАНА ЛИТЕРАТУРА}

Assmann 2005: Assman, J. Das kulturelle Gedächtnis. Schrift, Erinnerung und politische Identität in frühen Hochkulturen. München: C. H. Beck oHG. 
Burkart 2000: Burkart, R. Nauka za komunikatsiyata. Veliko Tarnovo: PIK [Буркарт, Р. Наука за комуникацията. Велико Търново: ПИК].

Canter 2018: Canter, D. The Psychology of place. Liverpool: University of Liverpool, 19 September <THEPSYCHOLOGYOFPLACEintroduction.pdf (status 21.03. 2021)>.

Gardner 2008: Gardner, H. The Mind's New Science: A History Of The Cognitive Revolution. New York: Basic Books.

Gardner 2014: Gardner, H. Mnozhestvoto inteligentnosti. Novi horizonti v teoriyata i praktikata. Sofia: Iztok-Zapad [Гардньр, X. Множеството интелигентности. Нови хоризонти в теорията и практиката. София: Изток-Запад].

Glasersfeld 2005: Glasersfeld, E. v. Die Wirklichkeit als Konstruktion. 13. 05. 2005. Retrieved from $<$ https://sciencev1.orf.at/news/135507.html (status 21.03.2021)>.

Isaacs 2011: Isaacs, W. Dialog als Kunst gemeinsam zu denken. Bergisch Gladbach: Verlag Andreas Kohlhage, 2. Aufl.

Kamenov 2006: Kamenov, K. Situatsii i povedenie na choveshkiya faktor $v$ upravlenieto. Veliko Tarnovo: Abagar [Каменов, К. Ситуации и поведение на човешкия фактор в управлението. Велико Търново: Абагар].

Kamenov 2008: Kamenov, K. Povedencheska adekvatnost i upravlenska ustoychivost. Veliko Tarnovo: Abagar [Каменов, К. Поведенческа адекватност и управленска устойчивост. Велико Тьрново: Абагар].

Kamenov 2012: Kamenov, $K$. Povedencheska neopredelenost i menidzarska pronitsatelnost. // Ikonomicheska misal, kn. 1 [Каменов, К. Поведенческа неопределеност и мениджърска проницателност. // Икономическа мисъл, кн. 1].

Koeva 2017: Koeva, Y. Nevrodidaktika v obuchenieto po nemski ezik kato chuzhd. Avtoreferat na disertatsiya za prisazhdane na nauchna stepen „doktor na pedagogicheskite nauki“. Sofia: Nov balgarski universitet, Departament „Romanistika i germanistika“ [Коева, Я. Невродидактика в обучението по немски език като чужд. Автореферат на дисертация за присьждане на научна степен „доктор на педагогическите науки“. София: Нов Български университет. Департамент „Романистика и германистика“].

Korpiun 2015: Korpiun, M. Dialog als Beziehungsgeschehen. - In: Riess-Beger, D. (Hrsg.): Zukunft denken - Wandel gestalten. Perspektiven zu persönlicher Entwicklung, gesellschaftlicher Veränderung und ökonomischem Erfolg. 1. Aufl, 167-179. <https://www.in-stability.de/_downloads/de/mediathek /artikel/Dialog_als_Beziehungsgeschehen.pdf (status 26.03. 2021)>.

Mayrhofer-Battlogg 2018: Mayrhofer-Battlogg, A. Dialogisch zum Erfolg. Die emergente Wirkung dialogischer (interner) Kommunikaton - unter neurowissenschaftlichen Aspekten. Dissertation zur Erlangung des akademischen Grades einer Doktorin der Staatswissenschaften im 
Fachbereich 6: Kultur- und Sozialwissenschaften der Universität KoblenzLandau $<$ https://d-nb.info/1164770179/34 (status 27.03. 2021) >.

Mengov 2014: Mengov, G. Ratsionalnost i intuitsiya $v$ choveshkite resheniya. $<\underline{\text { https://www.researchgate.net/publication/285345350 Rationality and I }}$ ntuition_in_Human_Decisions (status 24. 03. 2021)> [Менгов, Г. Рационалност и интуиция в човешките решения].

Messner, Blum 2006: Messner, R., Blum, W. Selbständiges Lernen im Fachunterricht. Kasseler Forschergruppe. Empirische Bildungsforschung. Kassel: Kassel university press.

Mohr 2006: Mohr, G. Dynamic organizational analysis. - In: Mohr, G., T. Steinert (eds.). Growth and change for organizations: Transactional analysis new developments 1995-2006. Pleasanton, CA: International Transactional Analysis Association, 79-101.

Sternberg, Williams 2014: Sternberg, R. J., W. M. Williams. Pedadogicheska psihologiya. Sofia: Iztok-Zapad [Стърнбърг, Р., У. Уилямс. Педагогическа психология. София: Изток - Запад].

Stoyanov 2015: Stoyanov, I. Inteligentnost i povedenie na menidzhara $v$ upravlenieto na organizatsiyata. // Dialog, 2. <https://dlib.unisvishtov.bg/bitstream/handle/10610/2382/DialogueBook2bul2015_29_45 .pdf? sequence $=1 \&$ isAllowed $=\mathrm{y} \quad($ status 20.03. 2021) $>$ [Стоянов, И. Интелигентност и поведение на мениджъра в управлението на организацията. // Диалог, 2].

Unseld 1990: Unseld, S. Künstliche Intelligenz und Simulation in der Unternehmung. Wissensbasierte Systeme im Dienste des Managements. Stuttgart: B.G. Teubner.

Vasilev, Chorbadziyska, Belyovska 2017: Vasilev, V., O. Chorbadziyska, Ts. Belyovska. Menidzhmant i upravlenski tehnologii. Sofia: Propeler [Василев, B., О. Чорбаджийска, Ц. Бельовска. Мениджмънт и управленски технологии. София: Пропелер].

\section{Електронни ресурси}

Комуникации в социалните системи $2007 \quad<\underline{\text { http://else.uctm.edu }}$ /users/3/books/Komunikacij-OET.pdf (status 20.03. 2021)>. 